http://dx.doi.org/10.21707/gs.v11.n02a01

\title{
ANÁlise DE POLÍTICAS SOCIOAMBIENTAIS IMPLICADAS NO CASO DE Deslizamento de terra no bairro Mãe Luiza em Natal / RN
}

\author{
Hugo Yuri Elias Gomes de Assis ${ }^{1}$, Pedro Henrique Cesar ${ }^{1}$, Juliana Garcia Vidal Rodrigues ${ }^{1}$, Edna \\ Guilherme dos Santos ${ }^{1}$, Camila Kayssa Dutra Targino ${ }^{1}$, Eliza Maria Xavier Freire ${ }^{2}$, Sueli Aparecida \\ MOREIRA $^{3 *}$
}

${ }^{1}$ Discente do Mestrado do Programa regional de pós-graduação em desenvolvimento e meio ambiente, Universidade Federal do Rio Grande do Norte ${ }^{2}$ Docente do Departamento de Botânica e Zoologia, Universidade Federal do Rio Grande do Norte

${ }^{3}$ Docente do Departamento de Oceanografia e Limnologia, Centro de Biociências, Universidade Federal do Rio Grande do Norte

*Autor correspondente: suelimoreira@yahoo.com.br

Recebido em 22 de novembro de 2015. Aceito em 18 de janeiro de 2017. Publicado em 30 de junho de 2017.

Resumo - Mãe Luíza é um bairro costeiro de Natal-RN, instituído pela Lei no 794 de 1958, que foi sendo povoado de forma não planejada. No ano de 2014, o referido bairro foi afetado por grande deslizamento de terra devido, dentre outros fatores, a fortes chuvas. O movimento geológico teve grande impacto socioambiental e desabrigou centenas de famílias carentes. A falta de conhecimento para efetividade das políticas socioambientais urbanas motivou a realização do presente estudo com o objetivo de analisar a adoção de tais políticas pelo Poder Público após o deslizamento de terra. O estudo é de natureza qualitativa de abordagem mista, cujos sujeitos envolvidos foram abordados enquanto atores sociais em contexto vulnerável. Com a análise das diversas nuances do bairro de Mãe Luiza, constatou-se que falta uma política pública socioambiental eficaz que oriente as relações socioambientais da comunidade local.

Palavras - chave: Vulnerabilidade Soclal; Impacto Socioambiental; Planejamento Urbano; Ecossistema Dunar.

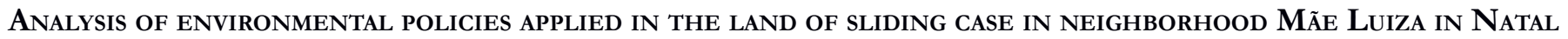
/ $\mathbf{R N}$

AbstraCt - In the year of 2014, Mãe Luiza neighborhood - Natal / RN experienced a large landslide caused by heavy rain added to other factors. This mass movement resulted in hundreds of homeless families and a large environmental impact on the site. This study addresses the problematic lack of knowledge about the effectiveness of environmental policies in the neighborhood. It aims to analyze the social and environmental public policies adopted by the Government after the accident in the neighborhood. The research is characterized as descriptive and exploratory because it takes into account the different social actors involved, and also the characterization of the study area. By analyzing the various nuances of Mãe Luiza neighborhood, it was noted a lack of an effective environmental public policy to guide the relationships of the local community.

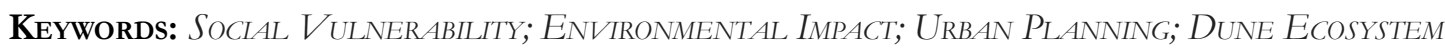

ANÁlisis de las políticas ambientales Relativas al deslizamiento de SUElo en la zona Mãe Luiza en Natal / RN

RESumen - Mãe Luiza es un barrio costero de Natal-RN, establecido por ley n ${ }^{\circ} 794$ de 1958, que fue siendo habitado sin planificacion urbana. En el año 2014, este barrio fue afectado por un gran deslizamiento debido a las lluvias torrenciales. El movimiento geológico tuvo gran impacto social y ambiental desabrigando cientos de famílias necesitadas. La falta de conocimiento de políticas urbanas y ambientales efectivas tuvo gran impacto social y ambiental y desabrigó cientos 
de familias. La falta de conocimientos para implementar políticas sociales y ambientales urbanas llevó a la realización de esta encuesta que tiene como objetivo analizar y adaptar políticas goviernamientales para después del hecho. Los métodos empleados son de carácter cualitativo con uma mescla de abordaje documental. Para esta investigación los sujetos afectados son considerados actores sociales en contexto vulnerable. El processo de análisis de los diversos matices del barrio "Mãe Luiza" carecen de una política pública mas eficaz en sus dimensiones social y ambiental para guiar el desarollo de la comunidad local.

Palabras clave: Vulnerabilidad Soclal; Impacto soclal y ambiental; Planificación urbana; Ecosistema de duna.

\section{INTRODUÇÃO}

A revolução industrial e a polarização local da economia favoreceram a concentração de pessoas em determinados lugares, ocasionando sérios problemas para o meio ambiente e a sociedade como um todo. Com a globalização e expansão do modelo econômico vigente, os problemas habitacionais agravaram-se, com reflexos negativos decorrentes da falta de planejamento urbano.

Como resultado da globalização uma nova percepção de riqueza é imposta, de prosperidade e de equilíbrio macroeconômico, conceitos baseados no dinheiro em estado puro e aos quais todas as economias nacionais são "pressionadas" a se adaptar a esse processo (Santos, 2000).

O cenário de desigualdade decorre da questão da ineficiência do sistema econômico e político vigentes, amplamente retratado por grandes pensadores como Karl Polanyi (1944), Thomas Piketty (2013), Amartya Sen (2010). Em busca dessa dimensão social, em atender às demandas básicas da população, como saneamento básico, acesso à saúde e educação, e sobretudo, a habitação digna, transformando a sociedade hoje, em um mosaico de inúmeras realidades desiguais e injustas do ponto de vista da qualidade de vida da sociedade, onde observamos um mundo de privações, destruição e opressão extraordinária (Sen, 2010).

Os resultados do atual modelo econômico apresentam cerca de $80 \%$ da população total vivendo em áreas urbanas, com a marcante presença de assentamentos populares precários, especialmente nos lugares ambientalmente frágeis, pois, representam a única alternativa para moradia de grande parcela da população (Martins, 2006).

Esses ambientes se caracterizam como áreas de risco; geralmente localizam-se próximas as margens de rios ou sobre encostas de morros com inclinação acentuada nas periferias urbanas onde as comunidades são expostas a desastres naturais oriundos da supressão total das matas ciliares e da impermeabilização do solo, como exemplifica Lima (2012).

As pessoas mais pobres tendem a ocupar áreas com ecossistemas frágeis devido à falta de oportunidades oferecidas a determinada parcela da população caracterizada principalmente pelo processo de favelização, suprimindo das comunidades liberdades substantivas as quais relacionam-se diretamente com a pobreza econômica, privando-as de obter uma nutrição satisfatória e a oportunidade de morar de modo apropriado, de ter acesso ao saneamento básico, entre outras liberdades (Sen, 2010). Caracterizando a vulnerabilidade ambiental onde, segundo Alves (2006, p. 01) consiste "na coexistência ou sobreposição espacial entre grupos populacionais muito pobres e com alta privação (vulnerabilidade social) e áreas de risco ou degradação ambiental (vulnerabilidade ambiental)".

No Brasil, o crescimento desordenado e a falta de um planejamento adequado para os grandes centros 
urbanos resultaram em construções em áreas de risco, muitas vezes, com sensíveis ecossistemas naturais acarretando em danos socioambientais irreversíveis, à exemplo: Zonas de Proteção Ambiental e Áreas de Preservação Permanente, localizadas em áreas urbanas que são continuamente ameaçadas por ocupações irregulares do ponto de vista legal e/ou ambiental.

Em meio a tantas transformações, a realidade segue o rumo da provisão, onde inúmeras famílias brasileiras estão construindo suas residências em áreas de risco, tendo em vista que a necessidade básica garantida pelo Art. $6^{\circ}$ da Constituição Federal de 1988 de direito à moradia, não está sendo garantida pelos entes responsáveis, demonstrando a ineficácia e insuficiência do sistema político e econômico, principalmente nas regiões onde se concentram bolsões de pobreza e onde as pessoas não tem representação política de modo organizado para reivindicar seus direitos.

O estado do Rio Grande do Norte, não divergindo da realidade demográfica de outros estados brasileiros, tem vivenciado ocupações indevidas nas consideradas áreas vulneráveis. Morais (2012) corrobora ao afirmar que as transformações socioeconômicas empreendidas no estado, marcadas pela globalização e crise socioambiental conduziram a uma trajetória de desenvolvimento insustentável, promove baixos níveis de renda e altos índices de pobreza, violência, déficits e precarização da moradia urbana, e elevado nível de pressão sobre os recursos naturais.

Nesse sentido, Mãe Luiza, localizado no município de Natal - RN é um bairro marcado pelas características supracitadas por Morais. Além disso, é ambiente de tensões entre as áreas do entorno, o setor hoteleiro, a gestão da Via Costeira e do Parque das Dunas, intensificadas pela ausência de uma política pública adequada aos objetivos de democratização da terra urbanizada (Mameri, 2014) e porque não, humanizada.

O bairro teve o início de sua ocupação por volta do final do século XX, denominada à época de "Morro do Bode" devido à vegetação rasteira que encobriam as dunas e atraiam os criadores de caprinos, que levavam seus rebanhos para pastar (Livecons, 2011). A ocupação do bairro foi marcada por uma série de acontecimentos que singularizaram a apropriação e a construção do seu espaço (Silva, 2003).

A falta de planejamento e ordenamento no nascimento do bairro de Mãe Luiza, seguido do descaso do poder público em relação à ocupação da região, fez com que as populações carentes se instalassem de forma desordenada nas áreas de riscos ou de vulnerabilidade ambiental, com possibilidade de deslizamento de terra (SILVA, 2003). Deslizamento de terra pode ser considerado segundo Macedo (2015), como um tipo de movimento de massa. Castro (1998) afirma que perigos acometem as populações residentes sobre certas condições socioambientais que, quando combinadas, produzem os eventos danosos sazonalmente no país.

A partir da década de 80, Macedo (2015) relata que no município de Natal foi instituído um Plano Diretor moderno, voltado para as demandas sociais, assim como preservação ambiental e conforto para a população habitante. A definição de Áreas Especiais de Interesse Social (AEIS’s) foi uma forma do poder público manter a cultura local tradicional, preservar comunidades carentes, residentes em locais com valor paisagístico e históricosocial, do interesse de expansão imobiliária nestes locais, em função da especulação imobiliária.

Com tudo, o bairro de Mãe Luiza ainda sofre com a ocupação desordenada, associado a isso e à dinâmica ambiental, junto com a falta de fiscalização por parte do poder público e seus órgãos competentes, em junho de 2014 ocorreu um deslizamento de terra no bairro, deixando diversas famílias desabrigadas onde, algumas tiveram suas casas comprometidas e consequentemente interditadas, e outras as perderam completamente.

Diante do exposto, este estudo tem como objetivo analisar as políticas públicas socioambientais adotadas 
pelo Poder Público durante e após o deslizamento de terra no bairro de Mãe Luiza em Natal - RN.

\title{
MATERIAIS E MÉTODOS
}

\author{
Área de estudo
}

O bairro de Mãe Luiza está localizado em uma área singular, ocupando uma continuação de cordão dunar na Zona Leste do município de Natal - RN, a qual caracteriza-se como Área de Preservação Permanente - APP, definida pela Lei $\mathrm{N}^{\circ}$ 12.651, de 25 de maio de 2012. O bairro foi legitimamente definido pela Lei $\mathrm{n}^{\circ}$. 794, de 23 de janeiro de 1958, na gestão do prefeito Djalma Maranhão (Macedo, 2015).

Está situado em área com formação geomorfológica característica de dunas, com fragilidades ambientais acentuadas no que diz respeito à erosão pela ação da água, pois é composta por um substrato arenoso na consolidação e com porosidade tal qual facilita a infiltração de água (Silva, 2003; Mameri, 2014).

O local conta com uma população estimada em 14.959 mil habitantes e 4.390 domićlios, segundo o Instituto Brasileira de Geografia e Estatística/IBGE (2010), e é considerada Área Especial de Interesse Social (AEIS) de acordo com a Lei Estadual No 4.663/95.

\section{Procedimentos metodológicos}

A pesquisa é de natureza qualitativa, com abordagens mistas. Abordagens mistas podem ocorrer concomitantemente de acordo com Creswell (2010 p.39). Sobretudo, foi considerada a ideia de pesquisa qualitativa de Jonker e Pennink (2010) cujo método visa compreender uma realidade organizacional especifica e fenômenos que ocorrem partindo da perspectiva dos envolvidos. Yin (1994) afirma que esse método se enquadra quando o pesquisador tem pouco controle sobre os eventos e o foco se encontra em fenômenos contemporâneos inseridos em algum contexto da vida real. Em complemento à análise documental, realizouse uma observação participante, conforme premissas adotadas por Minayo (2009, p.70) sobre "a necessidade que todo pesquisador social tem de relativizar o espaço social de onde provém, aprendendo a se colocar no lugar do outro". E isso só é possível pela proximidade com os interlocutores aponta Minayo (2009). Então, a observação participante foi realizada em duas abordagens: por meio de visitação no local e obtendo entrevistas semi-dirigidas, tendo como público alvo, tanto os moradores do bairro de Mãe Luiza em Natal/RN, afetados pelo deslizamento de encosta em junho de 2014, quanto os representantes dos órgãos públicos responsáveis pela assistência social, infraestrutura e meio ambiente.

\section{Observação Participante}

A pesquisa de campo por meio de observação participante foi desenvolvida em dois momentos, primeiramente foi realizada a visita na área atingida no mês de junho 2015 (um ano após o deslizamento), a fim de observar os efeitos do movimento de massa e quais ações estavam sendo implementadas pelo poder público. Posteriormente foi realizada visita in loco no mês de novembro do mesmo ano, a fim de atualizar as informações referente às ações de políticas públicas desenvolvidas no bairro. 
No local do deslizamento, buscou-se entrevistar moradores que foram por ele atingidos, totalizando um universo de 20 (vinte) atores, entre famílias que tiveram sua casa totalmente destruída e aquelas as quais a casa foi comprometida.

Objetivamos informações sobre as condições de moradia antes do sinistro, e como o poder público está agindo junto às famílias através de políticas públicas assistenciais após o deslizamento. Também foi entrevistado o engenheiro responsável pela obra de revitalização da encosta e reurbanização da área atingida, no intuito de entender como está se dando o andamento das obras de reurbanização, e quais as prioridades adotadas pela prefeitura no intuito de devolver aos moradores o local onde vivem e que possuem certo grau de topofilia.

O representante do Departamento de Ação Social e Projetos Especiais - DASPE vinculado à Secretaria Municipal de Habitação, Regularização Fundiária e Projetos Estruturantes - SEHARPE também foi entrevistado a fim de obter respostas sobre os atendimentos às famílias afetadas.

\section{Análise documental}

A análise documental foi baseada no Inquérito Civil no 06.2014.00003611-0 referente ao deslizamento em Mãe Luiza, de responsabilidade do Ministério Público Estadual do Rio Grande do Norte por meio da Promotoria do Meio Ambiente.

Esta fase da pesquisa também se desenvolveu em duas etapas: a primeira no mês de junho de 2015, onde obtivemos acesso irrestrito ao Inquérito Civil; e a segunda etapa realizada entre os meses de julho e novembro do mesmo ano.

Sobre a legislação vigente, o histórico e a situação da ocupação da região onde se localiza o bairro de Mãe Luiza e suas características ambientais foram consideradas diferentes publicações científicas sobre a área, legislações vigentes e os relatórios desenvolvidos sobre o bairro, assim como notícias publicadas por diferentes meios de comunicação a fim de se obter o máximo de informações possíveis sobre o histórico do bairro e sua situação atual.

Buscou-se informações nos órgão municipais: Companhia de Serviços Urbanos de Natal - URBANA, Secretaria Municipal de Trabalho e Assistência Social - SEMTAS, e - Secretaria Municipal de Habitação, Regularização Fundiária e Projetos Estruturantes -- SEHARPE para análise qualitativa das ações exercidas pelos poderes públicos supracitados.

As entrevistas foram fragmentadas em três dimensões: famílias atingidas pelo movimento de massa, engenheiro responsável pela obra de reurbanização do bairro após o incidente, e junto ao representante da Secretaria Municipal de Habitação, Regularização Fundiária e Projetos Estruturantes - SEHARPE no intuito de analisar as políticas públicas e ações emergenciais junto as famílias.

Quanto a avaliação dos impactos ambientais e análise das causas do deslizamento foram consultados relatórios desenvolvidos pelos órgãos: Companhia de Água e Esgoto do Rio Grande do Norte - CAERN; Universidade Federal do Rio Grande do Norte -UFRN e Instituto Federal do Rio Grande do Norte IFRN, através do relatório desenvolvido pelos professores: Dr. Ricardo Farias do Amaral, Dr. Ricardo Nascimento Flores Severo; e o Instituto de Desenvolvimento Sustentável do Rio Grande do Norte - IDEMA.

Por fim, foi realizada uma análise conjunta dos dados a fim de identificar contradições e incoerências nas ações adotadas pelos órgãos públicos no intuito de identificar os impactos das políticas públicas voltadas as 
questões socioambientais.

\section{REsultados E Discussão}

\section{Impactos Socioambientais}

Relatório do Serviço Geológico Brasileiro - CPRM

De acordo com o Relatório Técnico da CPRM, o deslizamento da encosta no Bairro de Mãe Luiza ocorreu devido à falta de estrutura do sistema de drenagem de águas pluviais, penetrando as partes expostas do terreno, o que provocou a segregação do sedimento arenoso, carreando grandes volumes à jusante, resultando na perda de sustentação, ruptura e queda de estruturas sobrepostas.

A principal constatação da equipe de geólogos da CPRM refere-se à completa impermeabilização do topo da duna, o que consequentemente forma uma imensa área de captação de águas pluviais; essas águas descem toda a encosta, seguindo a declividade do terreno, concentrando-se quase que totalmente pela rua Atalaia, desaguando no beco que dá acesso à rua Guanabara, onde o desnível é considerável potencializando a capacidade erosiva das águas.

O processo foi definido como uma erosão violenta que causou o desmonte hidráulico do material arenoso. Em síntese, o relatório faz um aparato dos principais aspectos intensificadores do desastre, tais como:

- Aspectos ambientais:

- Convergência e concentração de águas pluviais captadas em toda a face frontal da duna; e

- Impermeabilização de toda a área ocupada da duna,

- O gradiente da declividade e,

- Subdimensionamento da drenagem

- Aspectos socioambientais:

- Ausência de políticas públicas de controle urbano à época do início da ocupação;

- Alto número de casas à montante da encosta, construída a até mais de um metro abaixo do nível da rua;

- A área de deslize servia como depósito de lixo para os moradores; e

- O beco que fazia a ligação entre as ruas Atalaia e Guanabara era o maior concentrador de drenagem superficial, no entanto, esse canal de escoamento tinha pouco mais de dois metros de largura.

- Ações propostas para resolução do ocorrido:

- O controle da drenagem, para que as moradias não atingidas mantenham-se fora de risco;

- Aterramento da área com o próprio sedimento mobilizado, bem como instalação de, dentro do eixo de drenagem, barreiras intercaladas servindo de anteparo para fluxos de areia à Via Costeira.

Quanto às casas interditadas, o CPRM enfatizou em seu relatório que não seria preferível intervenção às mesmas, pelo menos à princípio, o que não impede uma demolição ou revitalização, porém, essa decisão fica a critério de engenheiros estruturais e geotécnicos. 


\section{Equipe de professores UFRN/IFRN}

A equipe caracteriza a área do deslizamento como sendo uma vertente ou encosta situada a leste, iniciada na Rua Atalaia e encerrando na Av. Governador Sílvio Pedroza.

A inclinação é de aproximadamente 20 graus, e seu comprimento é de aproximadamente 140 metros de comprimento e sua largura no trecho central está balizada pelas paredes dos edifícios Aldebram e Infinity. Segundo a equipe, a movimentação de terra gerou uma cicatriz profunda na vertente a qual a feição erosiva pode ser denominada de voçoroca. O voçorocamento atingiu a rua Guanabara, há aproximadamente 40 metros de altitude, mas se considerou que seu início se deu na rua Atalaia há 60 metros.

A vertente afetada corresponde ao campo de dunas "Parque das Dunas", e está assentada sobre sedimentos argilosos e siltosos do Grupo Barreiras, a qual esta unidade basal não fora atingida onde toda a massa sedimentar envolvida corresponde a areias da duna e entulhos (Oliveira, 2003)

Múltiplos fatores influenciaram para o desencadeamento da movimentação de terra. A equipe considerou dois pontos: Fatores Observados e Fatores Sugeridos:

Os fatores observados foram:

- Chuvas intensas no período, sendo considerado um evento extremo que suplantou em muito a capacidade de drenagem instalada na área;

- Supressão da vegetação natural da encosta;

- Impermeabilização do setor superior da encosta; e

- Confinamento de águas subterrâneas no sopé da encosta com elevação da superfície freática e indução à concentração do fluxo de água.

Os Fatores Sugeridos foram:

- Ligações de águas pluviais à rede de esgoto e ligações de esgotos domésticos à rede de drenagem pluvial provocando sobrecarga de fluxo;

- Subdimensionamento das redes de esgoto e de drenagem pluvial para eventos climáticos extremos;

- Obstrução da rede de drenagem de águas pluviais e de esgoto;

- Solução de drenagem superficial por becos e escadarias inadequada; e

- Alteração do fluxo natural de águas subterrâneas por obras de contenção no sopé da encosta.

In loco, a equipe constatou que:

- Houve destruição completa de cerca de cem metros da Rua Guanabara conjuntamente com as redes de energia elétrica, esgoto, água e galerias pluviais;

- Destruição completa ou parcial de pelo menos vinte ou mais residências;

- Risco iminente de deslizamento de pelo menos trinta ou mais residências entre as ruas Guanabara e Atalaia;

- Destruição completa da rede de esgoto e as galerias pluviais localizadas na encosta onde ocorreu o movimento de massa; e

- Movimentação estimada de cerca de $50.000 \mathrm{~m}^{3}$ de areia e detritos.

Após a visita e análise dos fatores observados e em reunião com a Prefeitura Municipal de Natal, a equipe sugeriu algumas ações: 
Ações sociais:

- Atendimento imediato e total a população atingida;

- Restabelecimento da energia e da rede de água onde fosse possível;

- Restabelecimento das comunicações e esclarecimento por parte das autoridades à população;

- Declaração que toda a Rua Guanabara e área circunvizinha constituíam uma região de auto risco de deslizamento ou moderado risco;

- Execução de programas sociais de educação e projetos de urbanização adaptadas à realidade local relacionadas à presença de lixo e entulhos, que podem obstruir as redes de drenagem e esgoto, bem como o processo de impermeabilização do solo no setor superior da encosta deve ser mitigado;

Ações Ambientais:

- Não intervenção momentânea de engenharia no local,

- Não colocação imediata de lonas plásticas e outras intervenções pontuais no local evitando com isso riscos aos trabalhadores nesse tipo de operação;

- Não remoção imediata do solo que está sobre a pista de Areia Preta servindo de berma de equilíbrio para o solo deslizado a montante;

- Vistoria em casas, ruas e terrenos na área da catástrofe com monitoramento por parte da Secretaria de Obras nesses locais, sendo designado um engenheiro da secretaria para manter esse monitoramento diário por um determinado tempo;

- Exigência da Prefeitura aos síndicos dos prédios de Areia Preta para que contatem seus construtores e/ou engenheiros calculistas para que verifiquem o funcionamento de suas cortinas atirantadas quanto aos drenos e indícios de movimentações e para verificação da capacidade estrutural para resistir ao impacto de novos deslizamentos que por ventura possam ocorrer na direção dos prédios.

- O confinamento parcial das águas subterrâneas no setor inferior da encosta, provocado pela presença de obras de proteção dos edifícios deve ser verificado em um projeto que analise a dinâmica das águas subterrâneas em toda a encosta atingida e nas proximidades;

- A recuperação da área destruída deve ser respaldada por um projeto que considere todos os elementos que envolvam a dinâmica das águas no setor: relevo, material geológico, rede de drenagem, rede de esgotos, rede de escoamento superficial, obras de contenção e questões relativas à urbanização;

- Sugere-se um projeto de diagnóstico e posterior monitoramento contínuo do comportamento das águas, superficiais e subterrâneas, nas encostas ocupadas, e a elaboração de um projeto de contingência; e

- Sugere-se o aproveitamento da área degradada para um projeto urbano de socialização, como forma de compensação à população atingida.

\section{CAERN - Companbia de Águas e Esgotos do Rio Grande do Norte}

O documento elaborado pela CAERN ao Ministério Público, datado de julho de 2014, apresenta uma breve caracterização do bairro, bem como os problemas e desafios relacionados ao abastecimento de água, esgotamento sanitário e de águas pluviais, onde deixa bem claro que a responsabilidade da coleta das águas pluviais é de responsabilidade exclusiva da prefeitura de Natal. 
O documento cita a falta de planejamento e de políticas públicas no início da ocupação da área com ações antrópicas negativas, como a execução de cortes e aterros, desmatamento e remoção da vegetação superficial, deposição de lixo, dentre outros fatores que contribuíram para a sua degradação e situação de risco das famílias ali assentadas.

Para recuperar a área atingida será necessário a recuperação das redes de água, esgoto e drenagem, onde, segundo a CAERN, o bairro de Mãe Luiza possui 1.972 ligações cadastradas, 2.209 economias, sendo 732 do tipo condominial, e 1.477 convencional.

Após trinta anos a grande maioria dessas tubulações (canos de ferro fundido para adutoras e linhas submetidas a grandes pressões, além de tubos de cimento amianto para redes e anéis de distribuição com menores pressões de trabalho) apresentam problemas, com funcionamento precário, principalmente devido ao conjunto de fatores abaixo enumerados:

- Obsolência das canalizações;

- Tráfego de veículos;

- Inexistência de material de reposição; e

- Riscos do amianto à saúde.

Para atender a área afetada no bairro de Mãe Luiza recomenda-se, segundo o documento, a troca da tubulação de cimento amianto por PVC, observando também que a área encontra-se toda adensada e com limitação de crescimento vertical como consta no Plano Diretor de Zoneamento da Prefeitura de Natal.

Faz-se necessário que haja a consciência plena por parte de todos de que, em Natal, não deverá existir em hipótese alguma a interligação entre os sistemas de água e esgoto, considerando que sempre que houver a contribuição das águas pluviais no sistema de esgotamento sanitário, o esgoto irá sofrer grandes prejuízos.

\section{IDEMA - Instituto de Desenvolvimento Sustentável e Meio Ambiente do Rio Grande do Norte}

O documento apresentado pelo IDEMA, datado em 03 de julho de 2014, consiste em um laudo técnico acerca do depósito de areia verificado na praia de Areia Preta e tem por objetivo avaliar, sob o aspecto ambiental, o depósito de areia que se encontrava na praia de Areia Preta, originado a partir do deslizamento de terra.

Em vistoria realizada no dia 18 de junho de 2014, foi constatado:

Aspectos Ambientais

- Acúmulo de areia na faixa de praia localizada em frente a área erodida, resultante do deslizamento de terra;

\section{Aspectos Socioambientais}

- Acúmulo de areia na faixa de praia localizada em frente a área erodida;

- Havia no local um movimento de máquinas e caminhões transportando a areia para outra área que fica nas proximidades de um canteiro de obras da empresa Ramalho Moreira, empresa esta responsável pelo transporte de areia. No entanto, verificou-se que a areia estava sendo colocada em área pública em frente a uma quadra sem nenhum cuidado para se evitar o contato com as pessoas que ali trafegavam; e

- O deslizamento provocou o rompimento da galeria de águas pluviais e da rede coletora de esgotos existentes na rua Guanabara onde as águas pluviais e esgotos estão sendo lançados na área erodida e seguem em direção à praia. 
No entanto, ao retornar no dia 20 de junho de 2014 ao local, a equipe constatou que com a retirada da areia da via pública o esgoto passou a se acumular na Avenida Governador Sílvio Pedroza e extravasar em direção à praia através de tubulação de águas pluviais situada defronte aos pontos comerciais da referida avenida.

Com relação ao deslocamento de areia depositada na praia, a Secretaria Municipal de Obras Públicas SEMOPI informou no dia 20 de junho de 2014 que não era mais pretensão levar essa areia para outro local, e sim utilizá-la para aterro da própria área onde ocorreu o deslizamento de terra

\section{Análise conjunta dos relatórios}

De acordo com o apresentado pelos órgãos acima é consenso que as ações, medidas e proposições em relação à questão socioambiental baseiam-se em:

- Necessidade de aplicação de diferentes intervenções relacionadas aos sistemas de drenagem e esgotamento da área, adequando-os as necessidades demandadas;

- Ações contínuas de educação ambiental em relação, principalmente, ao descarte inadequado de resíduos sólidos;

- Intervenções do poder público em relação ao ordenamento da ocupação territorial; e

- Fiscalização e acompanhamento contínuo da dinâmica do bairro.

Essas medidas, se de fato bem adotadas e aplicadas levando-se em consideração a opinião popular, visto que a participação pública é de extrema importância para o planejamento, implementação e sucesso das políticas públicas a serem adotadas (Buarque, 2008), irão contribuir para a manutenção das características naturais do bairro, assim como garantir seguridade socioambiental à população.

Porém, faltam ações conjuntas por parte dos órgãos acima citados, relacionadas à necessidade de desenvolver/efetivar políticas públicas envolvendo a comunidade num processo contínuo de Educação Ambiental e tomadas de decisão através da gestão participativa como bem coloca Buarque (2008), e é destacado por Sen (2015) como um dos fatores para desenvolvimento das populações, afinal, a intervenção antrópica foi um dos fatores preponderantes para que ocasionasse o deslizamento de terra, tanto no aspecto de não respeitar as obras estruturais de drenagem de águas pluviais e esgotamento sanitário realizando ligações clandestinas, como no que diz respeito a correta destinação dos seus resíduos sólidos.

No entanto, há diversos fatores que não permitem uma estreita relação entre sociedade e o ambiente, seja ele natural ou cultural, ou seja, é preciso que esses moradores sintam-se parte do ambiente e não apenas como um mero habitante, e sim como um agente de transformação socioambiental como vem ocorrendo historicamente no bairro através das lutas sociais (Silva, 2003).

\section{Análise de casos de deslizamento de terra}

Caso similar ao em estudo é o referente às chuvas torrenciais que ocorreram em janeiro de 2011, na Região Serrana do Rio de Janeiro (municípios de Nova Friburgo, Petrópolis e Teresópolis), ocasionando deslizamento de terra. Estabelecendo um paralelo observa-se que tais catástrofes incidem na maior parte dos casos em áreas de risco, nas quais há ocupação indevida por habitações e outros usos antrópicos.

Consoante Relatório de Inspeção da área atingida pela tragédia das chuvas na Região Serrana do Rio 
de Janeiro, Brasil (2011) as áreas mais atingidas pelos eventos climáticos são legalmente protegidas, em especial Áreas de Preservação permanente (APP’s), indevidamente ocupadas para atividades agrícolas, obras de infraestrutura e edificações. Vale salientar que o bairro de Mãe Luiza localiza-se em Área de Preservação Permanente, constituindo parte do Parque das Dunas.

O referido relatório destaca sobre processos intensificadores/determinantes para ocorrência dos deslizamentos: construções inadequadas em áreas de risco (APP’s), drenagem de águas, acúmulo de lixo, desmatamentos e falta de planejamento urbano, com lugares seguros para construção de residências.

O documento supracitado contém análises dos deslizamentos, onde se verifica que do total de deslizamentos ocorridos na área escolhida para ser analisada, 92\% ocorreram em áreas com algum tipo de alteração antrópica e somente $8 \%$ em áreas com vegetação nativa bem conservada, as quais não houveram alterações em seu entorno. Outro dado interessante é de que em cerca de 59\% dos deslizamentos havia um único tipo de intervenção. Importante ressaltar que a maioria dos deslizamentos ocorridos em áreas de vegetação nativa bem conservada se deu em razão de intervenção antrópica muito próxima.

Esses dados coadunam com os averiguados pelo Centro de Informações de Recursos Ambientais e Hidrometereologia de Santa Catarina (Epagri-Ciram), órgão do governo do estado de Santa Catarina, o qual mostra que 84,38\% das áreas atingidas pelo deslizamento na região do Morro do Baú - SC, ocorrido em 2008, haviam sido desmatadas ou alteradas pelo ser humano e somente 15,65\% dos desbarrancamentos ou deslizamentos ocorreram em área com cobertura florestal densa ou pouco alterada, tendo sido observadas incidências de ações humanas no entorno dessas áreas.

Nota-se que a maioria dos deslizamentos ocorre em áreas com alta declividade e topos de morro, consideradas pelo Código Florestal como áreas de preservação permanente ou de uso limitado quando respectivamente: áreas com declividade superior a $45^{\circ}$ e topos de morro; áreas entre $25^{\circ}$ e $45^{\circ}$ de declividade.

\section{A ação do Poder Público e as Políticas Públicas.}

O Poder Público está personificado nas pessoas jurídicas de direito público e opera por meio dos órgãos administrativos vinculados à própria esfera do poder público, conforme preleciona Mello (2010, p. 70):

O Poder Público se encontra em situação de autoridade, de comando, relativamente aos particulares, como indispensável condição para gerir os interesses públicos postos em confronto. Compreende, em face da sua desigualdade, a possibilidade, em favor da administração, de constituir os privados em obrigações por meio de ato unilateral daquela. Implica, outrossim, muitas vezes, o direito de modificar, também unilateralmente, relações já estabelecidas.

Dessa maneira, a Prefeitura Municipal do Natal, por meio de três das suas Secretarias: SEHARPE Secretária de Habitação, Regularização Fundiária e Projetos Estruturantes; SEMDS - Secretaria Municipal de Segurança Pública e Defesa Social; SEMTAS - Secretaria Municipal de Trabalho e Assistência Social prestou assistência imediata no atendimento à população atingida, retirando as famílias da área de risco e as alocando em abrigos provisórios, conforme relatório expedido pela SEHARPE, condizente com as entrevistas realizadas com os moradores afetados pela movimentação de terra.

Além das ações registradas, outras medidas foram observadas:

- Cadastramento das pessoas diretamente afetadas;

- Fornecimento de cestas básicas, vestuário, colchões, cobertores, materiais de limpeza, água potável e 
materiais de higiene pessoal em conformidade com o Ofício no 1901/2014 emitido pela SEMTAS e dirigido a $33^{\circ}$ Promotoria de Justiça.

Ainda no que tange as informações colhidas no documento supracitado, parte das famílias que tiveram seus imóveis afetados foram obrigadas a ir para residências de parentes e amigos e outras 35 (trinta e cinco) foram abrigadas em espaços improvisados pela Defesa Civil.

Tal situação perdurou até o advento da Lei no 6.473/2014, que instituiu o auxílio moradia no Município do Natal-RN e pelo Decreto Municipal no 10.352/14 que a regulamenta. A partir de então, os moradores atingidos pela movimentação de terra estão recebendo auxilio no valor de 1 (um) salário mínimo $\mathbf{R} \$ 788,00$ (setecentos e oitenta e oito reais), conforme informações obtidas no Ofício no 805/14 - GS/SEHARPE.

O pagamento do auxílio moradia tem prazo de 6 (seis) meses podendo ser prorrogado pelo mesmo período. O objetivo desta assistência é suprir a necessidade de pagar aluguel frente à impossibilidade dos moradores voltarem para suas residências.

O Ministério Público do Meio Ambiente instaurou Inquérito Civil nº 06.2014.00003611-0 em 18 de junho de 2014, com intuito de avaliar os danos ambientais ocorridos nos Bairros Mãe Luiza e Areia Preta bem como apurar a responsabilidade pelas ações e omissões que resultaram na degradação ambiental constatada e buscar a reparação dos danos ambientais e sociais detectados. Essa postura do Ministério Público vai de acordo com o que Alexandre (2004) apud Alexandre e Krischke (2006) ao afirmar que o órgão tornou-se um locus comum de discussão de temas ambientais.

Muito embora tenha sido instaurado em 2014, há mais de um ano, o Inquérito ainda não chegou ao fim. A Promotoria responsável se viu na necessidade de pedir dilação do prazo em função da proporção do desastre e suas muitas variáveis. O Promotor de Justiça Márcio Luiz Diógenes, em junho do presente ano, informou que pretendia ajuizar uma Ação Civil Pública - ACP quando estivesse na posse de novo relatório interdisciplinar solicitado a professores da UFRN, visando indenizar os moradores vitimados pelo deslizamento, o que ainda não foi possível até o momento em virtude da incerteza dos responsáveis.

No que diz respeito à atuação dos órgãos públicos, embora tenham sido praticadas várias ações no decorrer de mais de um ano do deslizamento no Bairro Mãe Luiza, a situação das populações atingidas ainda continua incerta.

\section{Obra de recomposição da encosta}

Em visitas realizadas in loco, em junho de 2015, o engenheiro responsável pela obra foi entrevistado, esclarecendo que as obras têm como função principal o tratamento e destinação adequada das águas superficiais a fim de evitar futuros deslizamentos de terra decorrente do escoamento superficial e possíveis infiltrações subterrâneas as quais podem deixar o substrato propenso ao deslizamento da encosta, além da devida captação do esgotamento sanitário da área atingida.

O referido engenheiro comentou também que houve alguns atrasos nas obras devido às chuvas que são normais para a região nos meses de junho e julho de 2015, e ao fato de um morador do bairro ter sido sugado pela tubulação no dia 21 de março de 2015 quando tentava desobstruir uma galeria próxima à residência, o que acarretou em sua morte.

As obras de reconstrução da área do deslizamento estão sendo conjuntamente encaminhadas, tanto as de 
micro e macrodrenagens, com a construção da escadaria que permitirá o acesso entre a Avenida Governador Sylvio Pedrosa no bairro de Areia Preta, e a Rua Guanabara no Bairro de Mãe Luiza finalizando com a pavimentação das ruas, atingidas, Atalaia e Guanabara (G1/RN, 2015).

Além da captação das águas pluviais e esgotamento sanitário, as obras visam conter a barreira a qual sofreu o deslizamento, bem como urbanização relacionada à acessibilidade com rampas para cadeirantes, escadas e um gramado, ou seja, um projeto paisagístico conforme pode ser visualizado na Figura 01.

Figura 1 - Projeto de reconstrução da área atingida pelo deslizamento Bairro de Mãe Luiza, Natal, RN. Fonte: Prefeitura de Natal, 2015 (disponível em http://www.natal.rn.gov.br/noticia/ntc-23065.html).

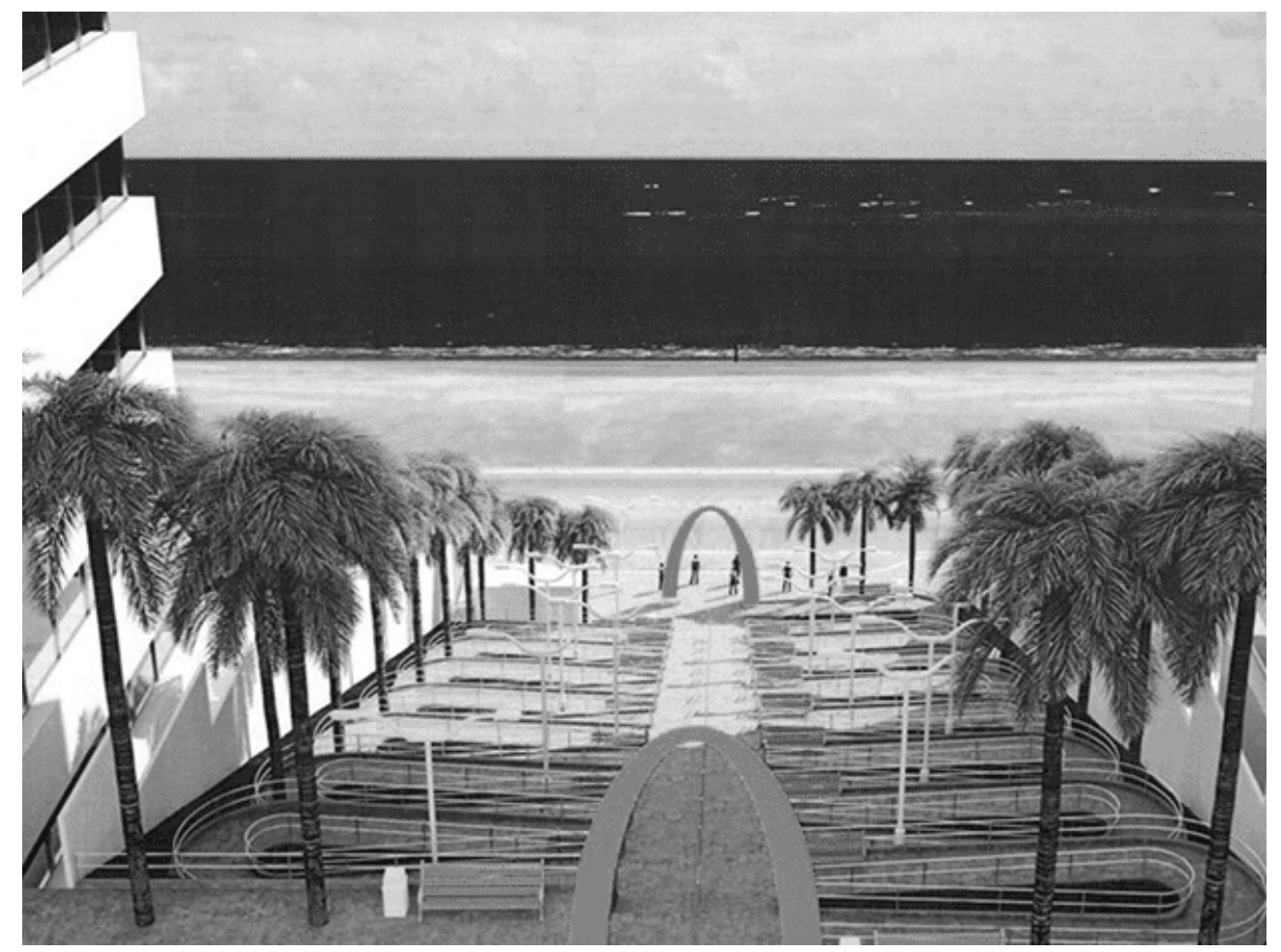

Retornando ao bairro em visita realizada no mês de novembro de 2015, pôde-se comprovar o avanço nas obras de revitalização da encosta e finalização da drenagem de águas pluviais da área, porém, algumas medidas que foram adotadas não conduzem a uma segurança socioambiental, como pode ser visualizado na Figura 2, pois foram instaladas caneletas de captação de águas nas ruas do bairro com o intuito de direcioná-las aos novos encanamentos instalados para sua captação de com grades de ferro na parte superior. Esta grade foi instalada em um único ponto, onde nos demais foram instaladas placas de concreto com maior espaçamento podendo ocasionar acidentes aos transeuntes, principalmente com crianças e animais, além do entupimento através de resíduos sólidos, pois os espaços vazios para penetração das águas pluviais são grandes, não levando em consideração que nas ruas o trânsito principal é feito por pedestres.

Nessa mesma visita, também foi possível visualizar que águas residuais estão sendo lançadas diretamente na faixa de praia, isso evidencia um fator preocupante, pois caso não haja uma intervenção à curto prazo, tais efluentes poderão acarretar em poluição, comprometendo o ambiente aquático. 
Figura 2 - A) Caneletas de captação de águas pluviais e B) Obras de revitalização da encosta (escadaria) no Bairro de Mãe Luiza, Natal, RN. Fonte: Prefeitura de Natal, 2015 (disponível em http://www.natal.rn.gov.br/noticia/ntc-23065.html).
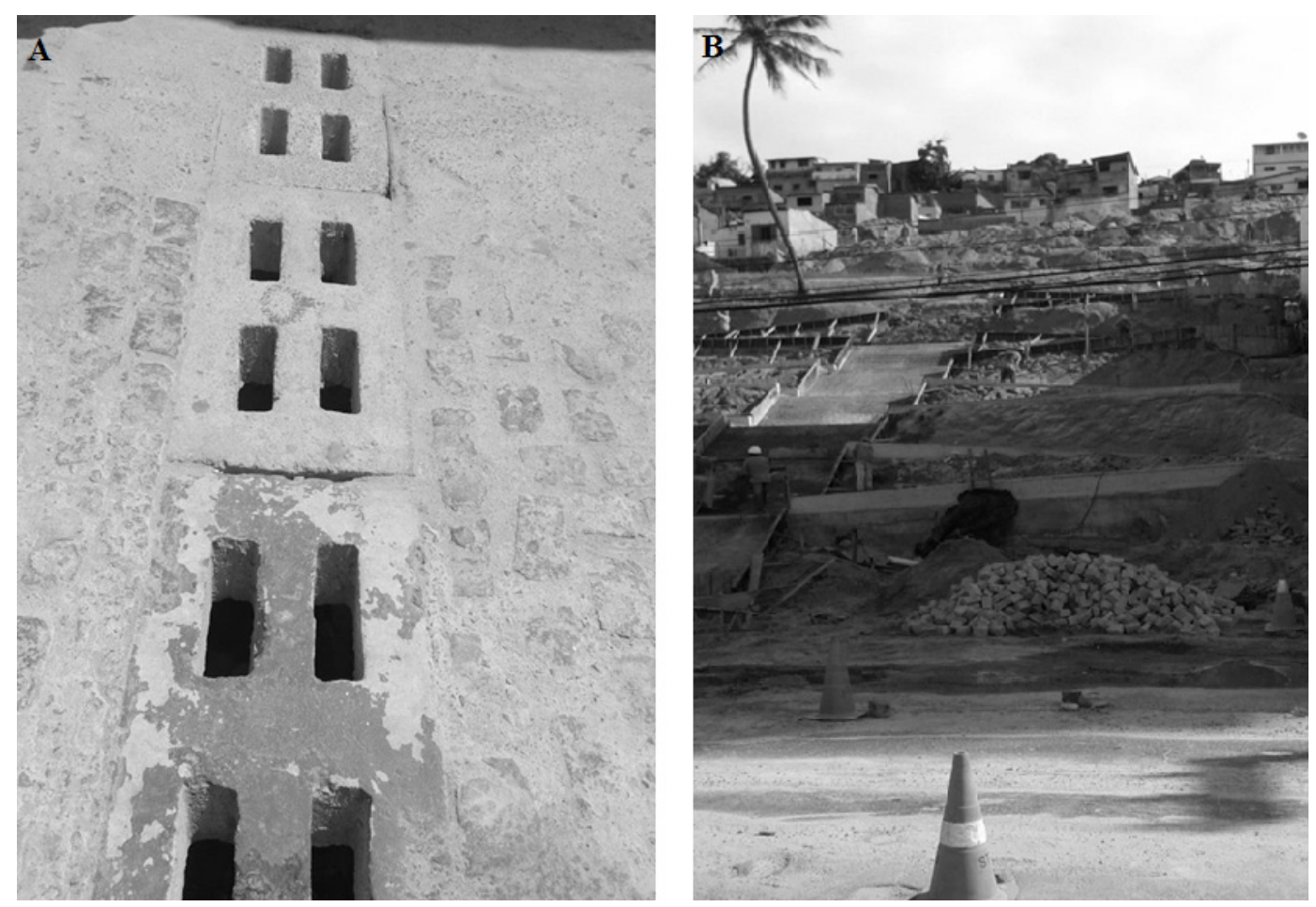

Politicas de assistência analisada a partir da percep̧̧ão dos atingidos

Dos entrevistados, a faixa etária se deu entre vinte e três e cinquenta e oito anos. Em relação ao tempo de moradia, 60\% dos entrevistados residem em Mãe Luiza desde seu nascimento simbolizando um enraizamento destes na cultura e desenvolvimento do bairro, criando-se assim um forte apreço topofílico. No que concerne aos proprietários dos imóveis, $80 \%$ declararam que as residências afetadas eram imóveis próprios. O número de pessoas que moravam em cada uma das casas se estabelece em uma média de 3,8 indivíduos.

Quando perguntado se os mesmos tinham consciência sobre o risco e a fragilidade do local ao decidirem residir, a grande maioria afirmou que não imaginava que tal fato pudesse acontecer. No entanto, parte dos entrevistados disseram que no ano de 1989 ocorreu um movimento de terra com menores proporções declarando que apenas seis casas foram afetadas e que a característica do terreno não foi muito abalada.

Ao serem indagados se a Defesa Civil, em algum momento, já havia alertado sobre a fragilidade da área ou sobre um possível deslizamento de terra, e se eram realizadas vistorias de maneira conjunta com o corpo de bombeiros de forma periódica, os moradores foram unânimes na resposta afirmando que a Defesa Civil não fez um alerta prévio sobre o risco de deslizamento o que caracteriza falta de monitoramento na referida área onde se faz necessária fiscalização periódica devido às características geomorfológicas e histórico de ocupação irregular. Essa situação mostra-se contrária à legislação, onde a Lei Federal 12.608/2012 enfatiza que é de competência do município "manter a população informada sobre áreas de risco, ocorrência de eventos extremos, protocolos de prevenção e alerta e ações emergenciais em circunstâncias de desastres” (Brasil, 2012).

Entretanto, o responsável pelo Departamento de Ação Social de Projetos Especiais (DASPE), o Senhor Mário Remi Marques Moreira, afirmou que no momento existe uma ação conjunta entre a Secretaria Municipal de Segurança Pública e Defesa Social (SEMDS), Secretaria Municipal de Trabalho e Assistência Social 
(SEMTAS) a qual integra a Defesa Civil, e a Secretaria Municipal de Habitação, Regularização Fundiária e Projetos Estruturantes (SEHARPE) realizando estudos na ânsia de evitar novos deslizamentos no bairro.

Sobre a questão da agilidade na assistência oferecida pela Defesa Civil e os Bombeiros no dia do deslizamento, todos os entrevistados afirmaram que houve a devida assistência, que se deu de forma muito eficiente, auxiliando na retirada dos moradores do local e disponibilizando veículo para ampará-los na mudança, além da distribuição de cestas básicas, água e colchões.

Os entrevistados também foram indagados sobre o local disponibilizado pelo poder público municipal; afirmaram que tanto a Defesa Civil quanto Corpo de Bombeiros realocaram algumas famílias para abrigos como a Escola Santo Reis. Algumas famílias alegaram que ficaram em torno de dois meses na escola e tiveram que sair após o reinício das aulas; algumas foram deslocadas para uma residência oferecida pela prefeitura e outras se responsabilizaram individualmente para encontrar um abrigo. Essa afirmação está de acordo com o relatório da SEHARPE que assegura que essa secretaria, através de sua equipe de assistentes sociais conjuntamente com a SEMTAS e SEMDES, atenderam as famílias no período noturno para a retirada da área de risco para os locais de abrigos provisórios.

Os entrevistados foram questionados se os subsídios ofertados pelo poder público municipal são suficientes para suprir as necessidades; alguns moradores se disseram insatisfeitos, pois após o deslizamento não havia assistências médica e social nos abrigos. Há relatos de falta de alimentos e gás. No entanto, a maioria dos indivíduos menciona que o auxílio moradia disponibilizado pelo governo municipal, através da SEHARPE no valor de $\mathrm{R} \$ 788,00$ (setecentos e oitenta e oito reais), acoberta o aluguel, a conta de energia e conta de água, sendo, após um ano do deslizamento, o único auxílio oferecido pelo poder público. De acordo com o relatório da SEHARPE o auxílio moradia foi elaborado por essa secretaria junto a Procuradoria Geral do Município. Concerne é um terno fora de moda. Em relação aos mecanismos de assistência à população desabrigada no momento do deslizamento de terra, o poder público municipal teve sua medida emergencial viabilizada, prevista também na Lei 12.608/2012, que é "prover solução de moradia temporária às famílias atingidas por desastres", no entanto tal medida deveria está alicerçada de forma a não negligenciar as famílias, seja por atraso ou falta do referido auxílio, onde alguns casos foram verificados no momento das visitas in loco.

A Lei 6.473/14 de julho e o Decreto 10.352/14 de 15 de julho instituíram e regulamentaram o Programa Auxílio Moradia no município de Natal, porém, na resposta ao questionário os moradores reclamam do atraso desse auxílio, tanto nas entrevistas realizadas em julho, quanto às realizadas em novembro. Um dos entrevistados, no momento em que estava sendo realizada a entrevista no mês de julho, estava fazendo sua mudança, pois foi despejado da casa onde morava por falta de pagamento do aluguel. Esse problema também foi abordado pelo representante do DASPE, entretanto, ele não apresentou nenhuma solução imediata para esse problema, mas que estavam buscando uma solução.

Referente às obras de reconstrução da área do deslizamento, os moradores foram unânimes em dizer que não recebem um retorno por parte da prefeitura - responsável pela obra - em relação ao encaminhamento das obras deixando os moradores apreensivos, pois como relatado em um dos relatórios do Ministério Público em julho, as famílias que tiveram suas casas interditadas só poderão fazer os reparos após a conclusão da obra; à época, o poder público não deu uma data limite para que as pessoas afetadas voltassem para suas residências.

Quando indagados sobre a posição dos órgãos públicos em relação à reconstrução das casas destruídas ou interditadas, alguns dos moradores afetados não souberam informar, pois a casa onde moravam era alugada; os 
outros (maioria entre os entrevistados) afirmaram que segundo a prefeitura a reconstrução das casas seria dada após a obra de drenagem ser finalizada.

No relatório da SEHARP, o órgão afirma que desenvolveu um estudo para a reconstrução das residências. O estudo tem por princípio a compreensão de que a alternativa mais adequada à realidade seria aquela que proporcionasse um reassentamento dessas famílias no mesmo bairro devido aos vínculos e direitos dessa população com o lugar. $O$ documento ainda informa que foram 25 (vinte e cinco) residências totalmente destruídas e que a equipe do Departamento de Desenvolvimento de Programas e Projetos analisou a área construída de cada casa demolida e a situação financeira das famílias residentes nelas.

A SEHARPE ainda informa que houve uma clara sinalização da viabilização de recursos através do programa Minha Casa Minha Vida (PMCMV) mediante uma operação conjugada com as obras de contenção, pavimentação, drenagem, abastecimento água e coleta de esgoto a ser realizada pela Secretaria Municipal de Obras Públicas (SEMOPI). O documento esclarece que mesmo frente à situação de emergência do caso, tal projeto deverá respeitar aos requisitos, princípios e normas do PMCMV, com toda a tramitação de projetos e documentações perante a Caixa Econômica Federal. Com isso, a SEHARPE desenvolveu duas propostas de tipos de moradia: uma com $45 \mathrm{~m}^{2}$ e outra com $80 \mathrm{~m}^{2}$ a ser implantado.

Em relação à área onde serão construídas essas residências o relatório diz que serão utilizados terrenos ociosos existentes no bairro. Já para as casas que não foram totalmente destruídas, os reparos serão feitos pela SEMOPI. No entanto, como já relatado pelos moradores, o relatório diz que essas obras só acontecerão quando a conclusão das obras de drenagens for finalizada.

Os moradores também foram indagados sobre a postura do poder público, e se eles se sentiam amparados e protegidos por este em um momento tão delicado como o que essas famílias vêm passando durante esse tempo; $20 \%$ se expressaram de forma satisfeita com o modo como o poder público atuou, se referindo ao auxílio moradia, contudo, $80 \%$ dos entrevistados disseram que a única coisa que eles têm é o auxílio moradia e que necessitam de mais informações sobre as obras, visitas de assistente social, assistência médica, ou seja, uma atenção maior por parte do estado relacionada ao acesso a serviços públicos, além do auxilia financeiro em emergências.

Durante a entrevista, na questão sobre o medo de voltar a morar no mesmo local, $50 \%$ disseram que tem medo de retornar, 30\% afirma que não tem receio de voltar para o mesmo local, e $20 \%$ diz que só voltaria caso houvesse mais segurança demostrando que grande parte das pessoas não tem mais a segurança que eles acreditavam ter antes do deslizamento de terra fazendo-se necessário todo um trabalho de apoio psicológico as famílias atingidas.

Em contato com a Secretaria Municipal de Trabalho e Assistência Social - SEMTAS foi possível obter algumas informações com a assistente social onde a mesma mencionou que no momento do ocorrido vários profissionais estiveram atuando na área prestando assistência às famílias. Quando indagada a respeito do acompanhamento psicológico às famílias, a mesma informou que no início havia, porém, atualmente esse acompanhamento fica a critério dos Centros de Referência de Assistência Social - CRAS no próprio bairro, onde pode haver obstáculos, caso haja grande demanda da população.

Após cinco meses da primeira visita foi possível constatar a passividade por parte do poder público para com as famílias atingidas. Ao entrevistar uma liderança do bairro podemos constatar que em relação às políticas públicas habitacionais a situação continua a mesma, segundo ele: "Prefeitura não fez nada de novo. Está tudo do 
mesmo jeito: uns recebem auxílio moradia (quando a prefeitura paga) outros não; e não reformam as casas que estão comprometidas e nem constroem as casas que foram destruídas."

O entrevistado tem uma visão muito lúcida em relação aos atrasos no auxílio moradia ao afirmar que o prefeito foi muito feliz quando disse que iria dar um auxílio moradia; porque auxílio moradia é diferente de auxílio aluguel; o auxílio moradia é um dinheiro para the ajudar onde você for morar, não condizendo necessariamente a um aluguel, ou seja, não tem o compromisso de um auxílio aluguel que necessita ser pago obrigatoriamente todo mês relata a liderança do bairro.

Como mencionado, anteriormente, o poder público não deu uma data limite para a entrega das casas. De acordo com o site de notícias G1, a Secretaria Municipal de Habitação afirmou que até o final do mês de julho de 2015 já se tinha uma empresa para iniciar as obras de recuperação das casas que não foram totalmente destruídas. Porém, como observado no relato do entrevistado até o momento nada foi feito.

Em segunda entrevista, um o morador afetado pelo deslizamento que perdeu sua casa com todos os seus pertences asseverou: "Perdi tudo! Tava viajando a trabalho quando cheguei não tinha mais nada. Até as roupas que uso são emprestadas; moro numa casa alugada, mas "tô" devendo o aluguel, o rapaz toda vez que me vê me cobra."

Podemos observar que o seu nome não integra a relação da SEHARPE - obtida na primeira visita ao Ministério Público em julho de 2015- das pessoas beneficiadas com o auxílio moradia. Ao indagá-lo sobre essa questão ele diz: "agora que recebi dois meses de auxílio porque coloquei uma advogada; a advogada ficou com uma metade e eu com a outra...”.

Ademais, conforme noticiado nos meios de comunicação, além de também ter sido relatado pelos morados, algumas casas antes interditadas pela Defesa Civil foram liberadas para que os moradores retornassem as suas residências. Com base nas entrevistas, nenhuma vistoria nos imóveis foi realizada pelos órgãos responsáveis que possibilitasse o retorno dos moradores com segurança.

Com isso, podemos averiguar que as políticas públicas habitacionais relacionadas ao deslizamento de terra no bairro de mãe Luiza estão muito aquém do necessário. Pessoas estão desamparadas em uma situação crítica, e o Estado não vos oferece o suporte necessário para que esses indivíduos vivam de forma salubre e honrada.

\section{Conclusão}

Podemos concluir que esse bairro se configurou a partir da má utilização do uso do espaço, e que o deslizamento de terra deu-se através da falta de monitoramento e fiscalização por parte dos órgãos públicos responsáveis cuja notoriedade mesmo diante do frágil ecossistema dunar, que caracteriza a região onde o bairro está situado, essa percepção de risco não tinha sido considerada até o incidente ocorrido.

Essa questão foi agravada pela inexistência de uma política pública permanente de educação e planejamento ambiental na área, além da falta ou ineficácia das políticas de planejamento urbano que objetivassem um melhor ordenamento da ocupação.

Identificamos a falta de comprometimento dos órgãos públicos a cerca de uma atenção permanente às famílias desabrigadas, resumindo toda a assistência social que deveria ser oferecida a essas pessoas, à um auxílio moradia que não vos é dado com compromisso, pois este é pago com atraso e acarreta em transtorno para esses indivíduos em um momento delicado. 
A comunidade de Mãe Luiza se mostra ativa desde sua gênese no tocante às reivindicações por direitos a acesso e aos serviços públicos que lhes é garantido por lei. Há tempos vem lutando e não se acomodando face às injustiças sociais, falta de políticas públicas e a força do capital oriundo da indústria hoteleira e especulação imobiliária que tenta diariamente retirar a comunidade de um dos pontos de mais bela paisagem da cidade de Natal.

Encerra-se essa pesquisa com a certeza de que a atenção, ou a falta de atenção por parte do poder público para com as comunidades mais carentes, em específico ao caso de Mãe Luiza, gera um impacto negativo fortíssimo, privando a comunidade dos serviços básicos e políticas socioambientais fundamentais para a melhoria da qualidade de vida da comunidade e desenvolvimento sustentável, que além de possuir uma beleza cênica deslumbrante, possui importância ecológica notável.

\section{REFERÊNCIAS}

Alexandre AF; Krischke PJ. Aspectos Institucionais das Políticas de Sustentabilidade do Brasil. In: Revista Internacional de Interdisciplinaridade INTERTHESES, v 3 n² 2, 2006.

Brasil. Constituição da República Federativa do Brasil. 1988.

Brasil. Ministério do Meio Ambiente. Relatório de Inspeção Área atingida pela tragédia das chuvas Região Serrana do Rio de Janeiro. Brasília: Secretaria de Biodiversidade e Florestas; 2011.

Brasil. Câmara dos Deputados. Gestão de desastres no Brasil. Lei 12.608/2012. Disponível em: http:// www2.camara.leg.br/documentos-e-pesquisa/publicacoes/estnottec/areas-da-conle/tema14/2012_16213.pdf. Acesso em 19.11.2015

Castro, ALC. Glossário De Defesa Civil: Estudo De Risco E Medicina De Desastres. Ministério do Planejamento e Orçamento. Brasília. 1998, 283p.

Chaves SVV. Riscos, Perigo e Vulnerabilidade em Áreas Urbanas: Uma Discussão Conceitual. IV Encontro Nacional da Anppas. Brasília - DF - Brasil. 2008

DAGNINO, Ricardo de Sampaio; JUNIOR, Salvador Carpi. RISCO AMBIENTAL: Conceito e Aplicações. Revista Climatologia e Estudo de Paisagem, Vol. 2- n. 2, p. 50, julho/dezembro, 2007.

HighlandLM.; BobrowskyP.O Manual de Deslizamento-Um Guia para a Compreensão de Deslizamentos. U.S. Virginia: Geological Survey, Reston; 2008.

Hogan DJ; Cunha JMP; Carmo RL; Oliveira AAB. Urbanização e Vulnerabilidade socioambientais diferenciadas: o caso de Campinas. Anais do XVII Encontro de Estudos Populacionais da ABEP. Belo Horizonte, MG: ABEP, 2000.

IBGE, Ins http://www.censo2010.ibge.gov.br/sinopseporsetores/?nivel=st

Lima HAS. Do Acesso Clássico à Comercialização: Especificidades do Mercado Imobiliário Informal na 
Área de Interesse Social de Mão Luíza, Natal/RN. Dissertação de Mestrado. Programa de Pós-Graduação em Arquitetura e Urbanismo (PPGAU) da Universidade Federal do Rio Grande do Norte (UFRN). Natal - RN. 2012.

Livecons. Plano de Gestão do Bairro de Mãe Luiza. Consultoria em Habitação e Qualidade de Vida. < www. livecons.co.cc > Acesso em: 20/10/2015

Macedo. Yuri Marques Macedo. Vulnerabilidade Socioambiental no bairro de Mãe Luiza, Natal/RN. Dissertação apresentada para obtenção do título de mestre em Geografia, Universidade Federal do Rio Grande do Norte, Natal, 2015. 182 p.

Mameri, SF; Bentes MD. Intervenções urbanas, ambiente e cotidiano em APPs: Inadequações e possibilidades nas experiências do bairro Mãe Luiza - Natal/RN. III Seminário Nacional sobre Tratamento de Áreas de Proteção Permanente em Meio Urbano e Restrições Ambientais ao Parcelamento do Solo. Belém do Pará - PR. APP Urbana. 2014.

Martins, MLR. Moradia e Mananciais. Tensão e diálogo na metrópole. São Paulo, FAUUSP/FAPESP, 2006.

Mello, CAB. Curso de Direito Administrativo. 27. ed.São Paulo: Malheros Editores LTDA, 2010.

Minayo, MCS. Trabalho de Campo: Contexto de observação, interação e descoberta. In Minayo, M.C.S.; Deslandes, S.F.; Gomes, R. Pesquisa Social: Teoria, método e criatividade. Petrópolis, RJ: Vozes; 2009.

Morais IRD. Planejamento e Desenvolvimento Regional: notas sobre a experiência do Rio Grande do Norte. Sociedade e Território, Natal, v, 24, nº 1, p. 77 - 96, jan/jun. 2012.

Nogueira FR. Gerenciamento de riscos ambientais associados a escorregamentos: contribuição às políticas públicas municipais para áreas de ocupação subnormal. 262 p. Tese de Doutorado, Rio Claro: UNESP, 2002.

Oliveira FFG. Caracterização E Diagnóstico De Impactos Ambientais Em Natal/RN Com Apoio De Geoprocessamento. Dissertação (Mestrado em Geografia) - UFRN, Natal, 2003.

Riberito LCQ. Vulnerabilidade Socioambiental das Regiões Metropolitanas Brasileiras. Observatório da Metrópoles - IPPUR/FASE. Letracapital. 2009.

Santos BS. Para além do Pensamento Abissal: Das linhas globais a uma ecologia de saberes. Revista Crítica de Ciências Sociais, n. 78, p. 3-46, out. 2007.

Santos, M. Por uma outra globalização - do pensamento único à consciência universal. Rio de Janeiro: Record, 2006.

SEBRAE - MG. Políticas públicas: Conceitos e práticas. 48 p. Série Políticas Públicas, volume 7. Minas Gerais, 2008. 
SEMURB. Conheça melhor o seu bairro: Mãe Luiza. Secretaria de Meio Ambiente e Urbanismo. Departamento de Informação, Pesquisa e Estatística. Setor de Pesquisa e Estatística. 2008.

Sen A. Desenvolvimento como Liberdade. Tradução: Laura Teixeira Motta. São Paulo/ SP. Editora Companhia das Letras. 2010

Silva AL. "A morada do(a) teimoso(a)": as práticas socioambientais de resistência em Mãe Luiza/ Natal - um território (in)sustentável. Tese de doutorado. Universidade Federal de Pernambuco - UFPE. Recife. 2013.

Sigaud L. Efeitos sociais de grandes projetos hidrelétricos: as barragens de Sobradinho e Machadinho. In: SIGAUD, Lygia, ROSA; Pinguelli, Luiz; MIELNIK, Otávio (Orgs.). Impactos de grandes projetos hidrelétricos e nucleares: aspectos econômicos, sociais e ambientais. São Paulo: Marco Zero, Rio de janeiro: UFRJ/COPPE, 1970. p. 83-166.

Souza, C. Políticas Públicas: uma revisão da literatura. Sociologias, n. 16º, p. 20-45, jul/dez 2006.

Tribuna do Norte. Disponível em < http:/ /www.tribunadonorte.com.br/noticia/geologos-do-sgb-recomendamreforco-estrutural/286019\%3E > Acesso: 10/11/2015 